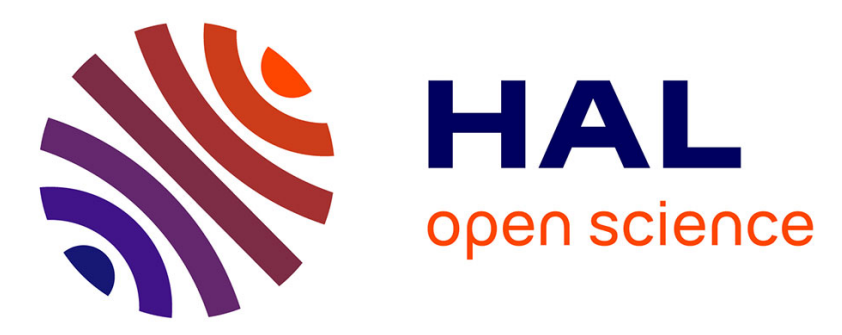

\title{
Application of dynamical ion mixing techniques to the improvement of the fatigue resistance of a $316 \mathrm{~L}$ stainless steel
}

\author{
P. Villechaise, J. Mendez, J. Delafond
}

\section{To cite this version:}

P. Villechaise, J. Mendez, J. Delafond. Application of dynamical ion mixing techniques to the improvement of the fatigue resistance of a 316L stainless steel. Journal de Physique IV Proceedings, 1993, 03 (C7), pp.C7-135-C7-138. 10.1051/jp4:1993721 • jpa-00251844

\section{HAL Id: jpa-00251844 https://hal.science/jpa-00251844}

Submitted on 1 Jan 1993

HAL is a multi-disciplinary open access archive for the deposit and dissemination of scientific research documents, whether they are published or not. The documents may come from teaching and research institutions in France or abroad, or from public or private research centers.
L'archive ouverte pluridisciplinaire HAL, est destinée au dépôt et à la diffusion de documents scientifiques de niveau recherche, publiés ou non, émanant des établissements d'enseignement et de recherche français ou étrangers, des laboratoires publics ou privés. 


\title{
Application of dynamical ion mixing techniques to the improvement of the fatigue resistance of a $316 \mathrm{~L}$ stainless steel
}

\author{
P. VILLECHAISE, J. MENDEZ and J. DELAFOND*
}

\begin{abstract}
Laboratoire de Mécanique et Physique des Matériaux, URA 863 du CNRS, ENSMA, rue Guillaume VII, 86034 Poitiers, France

${ }^{*}$ Laboratoire de Métallurgie Physique, URA 131 du CNRS, Université de Poitiers, 40 avenue du Recteur Pineau, 86022 Poitiers cedex, France
\end{abstract}

\begin{abstract}
In the last years new techniques involving ion implantation combined with a simultaneous deposition method in a sputtering evaporator have been developed at the University of Poitiers. These techniques have been employed to elaborate NiTi amorphous coatings in order to improve the fatigue resistance of a $316 \mathrm{~L}$ austenitic stainless steel at room temperature and $573 \mathrm{~K}$. It has been shown that a significant improvement of the fatigue life is obtained by this way at $293 \mathrm{~K}$ and at $573 \mathrm{~K}$ due to a considerable modification of surface damage leading to an important delay for crack initiation.
\end{abstract}

\section{INTRODUCTION}

The role of the surface in the fatigue resistance of homogeneous metallic materials is pre-eminent since fatigue failure generally occurs from cracks which initiate at the surface and then propagate progressively into the bulk. Moreover, crack initiation and first stages of crack growth are highly assisted by the environment even at room temperature. Therefore, the development of surface treatments and especially coatings in order to improve simultaneously the material resistance to crack initiation and oxidation will be of major interest. In the last decade ion implantation techniques have been considerably developed over the world. These techniques appeared very usefull to modify the near surface properties of metallic materials by creating suitable alloying and compressive residual stresses.

However in spite of strong modifications of the surface deformation conditions in cyclically deformed metals we have shown that only small effects can be obtained on crack initiation and growth stages with direct ion implantation due to the small thickness of the implanted layer $(\sim 0.1 \mu \mathrm{m})[1,2]$. To overcome these problems new techniques of dynamic ion mixing that involve ion implantation combined with a simultaneous deposition method have been developed [3]. These new low temperature deposition processes use intense and broad ion beams to bombard the growing film. Energetic ions produce dense displacement cascades and can induce an effective collisional mixing at the interface giving an increased adhesion to the substrate. Such a method permits the formation of thick coatings of the order of a micrometer with a well controlled microstructure difficult to obtain by other methods. This system is schematically represented in Fig.1.

We have applied this method to improve the fatigue resistance of different materials $[4,5]$. This paper presents the results concerning the effects of NiTi coatings elaborated by dynamical ion mixing (DIM) on the fatigue properties at $293 \mathrm{~K}$ and $573 \mathrm{~K}$ of a $316 \mathrm{~L}$ type austenitic stainless steel. Such deposits exhibit an amorphous structure with very strong hardness $(\simeq 1100 \mathrm{Hv})$.

The experiments have been performed in tension compression under plastic strain control with a plastic 
specimens were carefully polished up to a diamond $0.25 \mu \mathrm{m}$ grade. NiTi films of different thicknesses from $0.17 \mu \mathrm{m}$ to $1.35 \mu \mathrm{m}$ have been used.

\section{EFFECT ON CYCLIC BEHAVIOUR AND FATIGUE DAMAGE AT ROOM TEMPERATURE}

The evolution of the stress amplitude $\Delta \sigma / 2$ with the number of cycles in air at $293 \mathrm{~K}$ is given in Fig. 2 for the untreated and some typical NiTi coated specimens with coating thicknesses variing between 0.2 and $1.3 \mu \mathrm{m}$. Three plastic strain amplitudes are considered here $\Delta \varepsilon_{\mathrm{p}} / 2=6.6 \times 10^{-4}, 1 \times 10^{-3}$ and $2 \times 10^{-3}$. It can be seen that the cyclic behaviour of the untreated material is characterized by a short and weak primary hardening followed by a softening period which leads to a saturation stage.

It is clear that the deposit does not modify the macroscopical cyclic behaviour of the stainless steel, but that a substantial beneficial effect on fatigue life is obtained with NiTi coatings especially at low amplitude levels. In this case an important secondary cyclic hardening is observed leading to a significant increase of the cyclic stress level. This stress evolution must not be related to a direct mechanical effect due to the NiTi film but is the consequence of the prolonged cycling allowed by the treatment.

The effect of NiTi coating on the fatigue life and the role of the coating thickness are illustrated in Fig. 3 by the Coffin-Manson $\left(\Delta \varepsilon_{\mathrm{p}} / 2-\mathrm{N}_{\mathrm{f}}\right)$ curves for the uncoated and coated material. Even for the smaller thickness of NiTi investigated here, a significant increase in fatigue life is obtained; this effect is observed to increase with the film thickness in particular for low strain amplitudes. The number of cycles to failure is increased by a factor 1.5 with the $0.2 \mu \mathrm{m}$ coatings and by a factor 2 to 3 with the $0.5 \mu \mathrm{m}$ coatings. Moreover, with the $1.35 \mu \mathrm{m} \mathrm{NiTi}$ film, a sample has been cycled under $\Delta \varepsilon_{\mathrm{p}} / 2= \pm 6.6 \mathrm{x} 10^{-4}$ up to near $3 \times 10^{6}$ cycles without failure, that is 17 times the fatigue life of the uncoated samples. At the opposite, no additional beneficial effect in fatigue life has been obtained at $\Delta \varepsilon_{\mathrm{p}} / 2= \pm 2 \times 10^{-3}$ when the coating thickness is increased from $0.5 \mu \mathrm{m}$ to $1.35 \mu \mathrm{m}$.

Fig. 4 shows the aspect of the surface deformation of the untreated and coated material after cycling to failure under $\Delta \varepsilon_{p} / 2=6.6 \times 10^{-4}$. For the uncoated material surface deformation is characterized by isolated intense slip bands in which microcracks initiate. A quantitative evaluation of the surface fatigue damage shows that several thousands of microcracks form in this specimen after the 170,000 cycles corresponding to its fatigue life. In contrast only one or two cracks are observed on the treated specimen after 506,000 cycles. In general the deposit is not deteriorated by cyclic deformation but flakes off near the main crack ; that permits to reveal that NiTi coatings lead to a more homogeneous slip distribution near the interface favouring the material resistance to crack initiation.

\section{EFFECTS OF THE NITI COATINGS AT $573 \mathrm{~K}$.}

Fig. 5 shows the cyclic beaviour at $573 \mathrm{~K}$ of an untreated sample and a $1.3 \mu \mathrm{m}$ NiTi coated sample cycled in air under $\Delta \varepsilon_{\mathrm{p}} / 2=6.6 \times 10^{-4}$.

A strong increase in fatigue resistance is also obtained at this temperature with the treatment; this is accompanied as at room temperature by a marked modification of the surface damage. However it must be noted that this effect is reduced compared to the one observed at $293 \mathrm{~K}$ since for the conditions considered in Fig. 5 the fatigue life is multiplied by a factor of 5 while it is increased by more than 17 times at room temperature. This result confirms the important role of the environment in the fatigue damage processes of NiTi coatings as we have pointed it out in a previous paper [6].

The cyclic behaviour at $573 \mathrm{~K}$ is different than at $293 \mathrm{~K}$ and is characterized by a marked regular secondary hardening which continues up to failure in air without reaching a saturation stage. Therefore prolonging the life by the treatment permits to prolonge the increase of the stress amplitude reached at failure but no difference exists between the untreated and coated specimens in the common part of their life. 


\section{CONCLUSIONS}

We have applied Dynamical Ion Mixing to elaborate thin amorphous NiTi coatings in order to improve the fatigue resistance to crack initiation of a $316 \mathrm{~L}$ stainless steel at two temperature levels $293 \mathrm{~K}$ and $573 \mathrm{~K}$.

The treatment does not change the macroscopical behaviour of the specimens but the conditions of cyclic deformation in the grains near the specimen surface are strongly modified ; in particular a high homogenization of the deformation is produced which favours the resistance of the coating to shearing. As a consequence a significant increase of the fatigue life is obtained at room temperature even with the thinner deposits $(0.2 \mu \mathrm{m})$; this improvement becomes considerable with a $1.3 \mu \mathrm{m}$ deposit when the material is cycled at a low plastic strain amplitude.

First fatigue experiments performed at $573 \mathrm{~K}$ have shown similar beneficial effects. However the increase of the fatigue life obtained at this temperature is smaller due to oxidation effects.

\section{REFERENCES}

[1] J. MENDEZ, P. VIOLAN and J.P. VILLAIN, Scripta Met., Vol. 16, pp. 179-182 (1982).

[2] J. MENDEZ, P. VIOLAN and M.F. DENANOT, Nucl. Inst. and Meth., B 19/20, pp. 232-235 (1987).

[3] M. JAULIN, G. LAPLANCHE, J. DELAFOND, S. PIMBERT, Surface and Coating Technology 37 (2), p. 225 (1989).

[4] P. VILLECHAISE, J. MENDEZ and J. DELAFOND, "Surface Modification Technologies IV", T.S. Sudarshan, D.G. Bhat and M. Jeandin Editors, TMS pp. 335 (1991).

[5] P. VILLECHAISE, J. MENDEZ, P.VIOLAN and J.P. RIVIERE, Nucl. Instr. Meth ind Phys. Res. B59/60, pp. 837 (1991).

[6] J. MENDEZ, P. VILLECHAISE, P. VIOLAN and J. DELAFOND, "Corrosion-Déformation Interactions, CDI, 92" Fontainebleau, October 5-7, 1992, To be published.

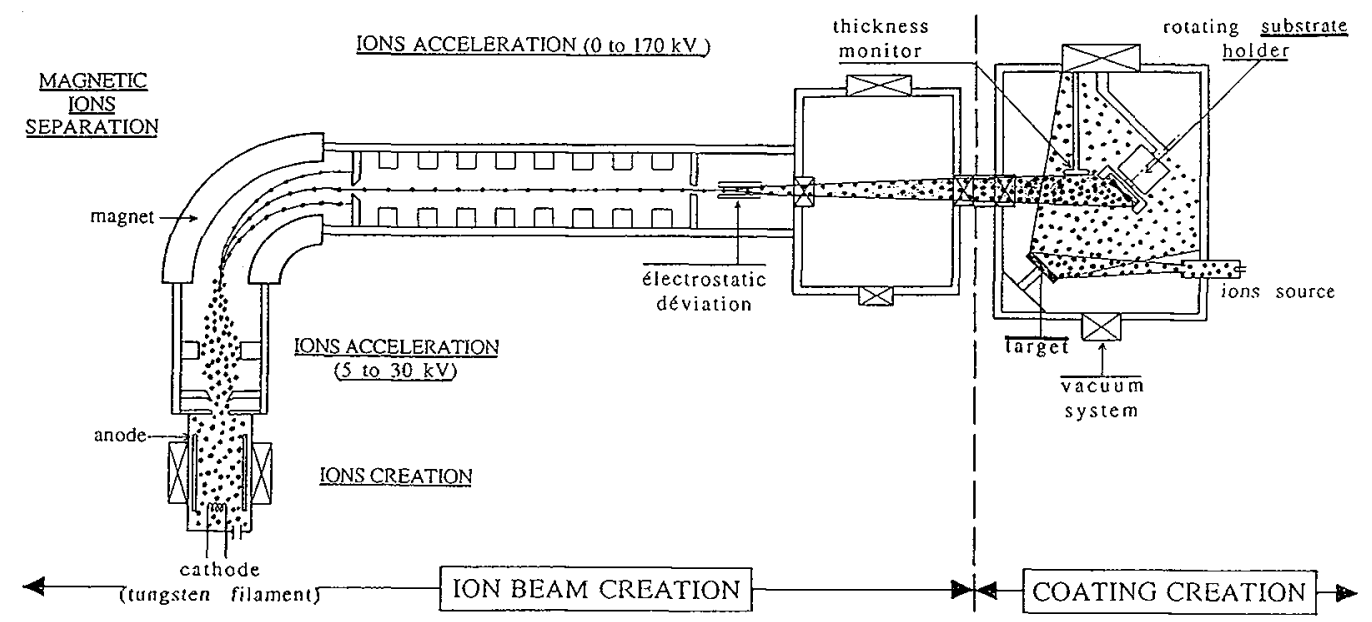

Fig.1. A schematic view of the sputtering evaporator and the ion implantor constituting the dynamical ion mixing system. 

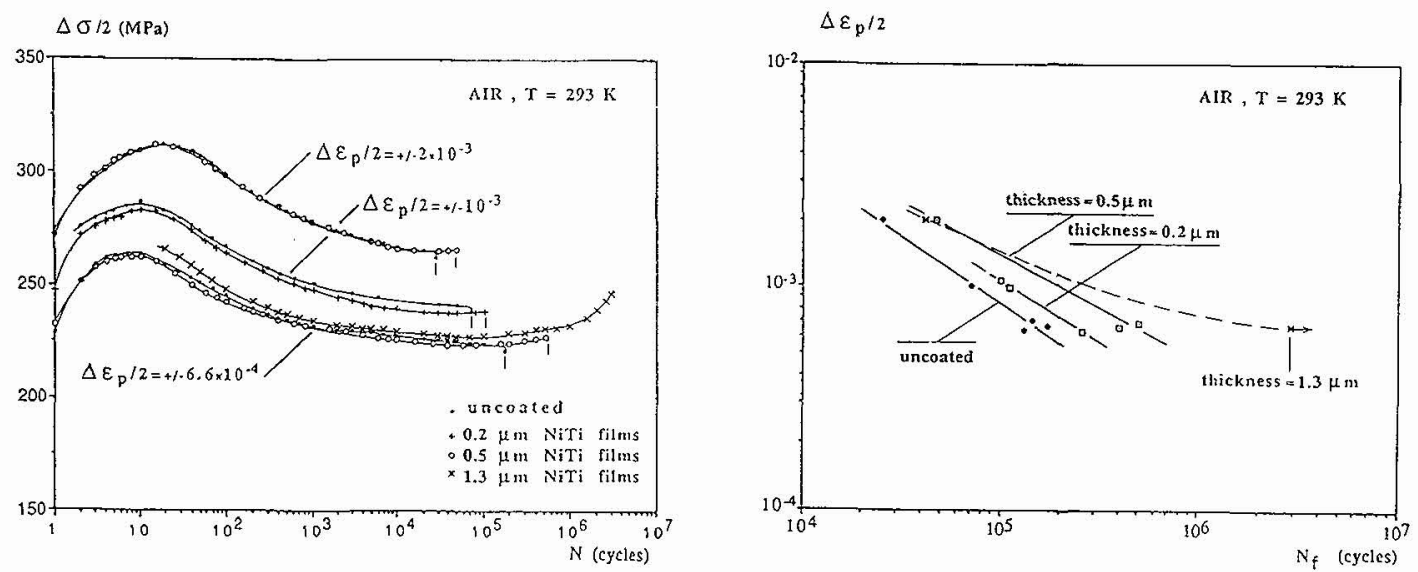

Fig. 2 - Cyclic behaviour of the untreated and $\mathrm{NiTi}$ coated specimens at $293 \mathrm{~K}$ in air.

Fig. 3 - Manson-Coffin curves of the untreated and $\mathrm{NiTi}$ coated specimens at $293 \mathrm{~K}$ in air.

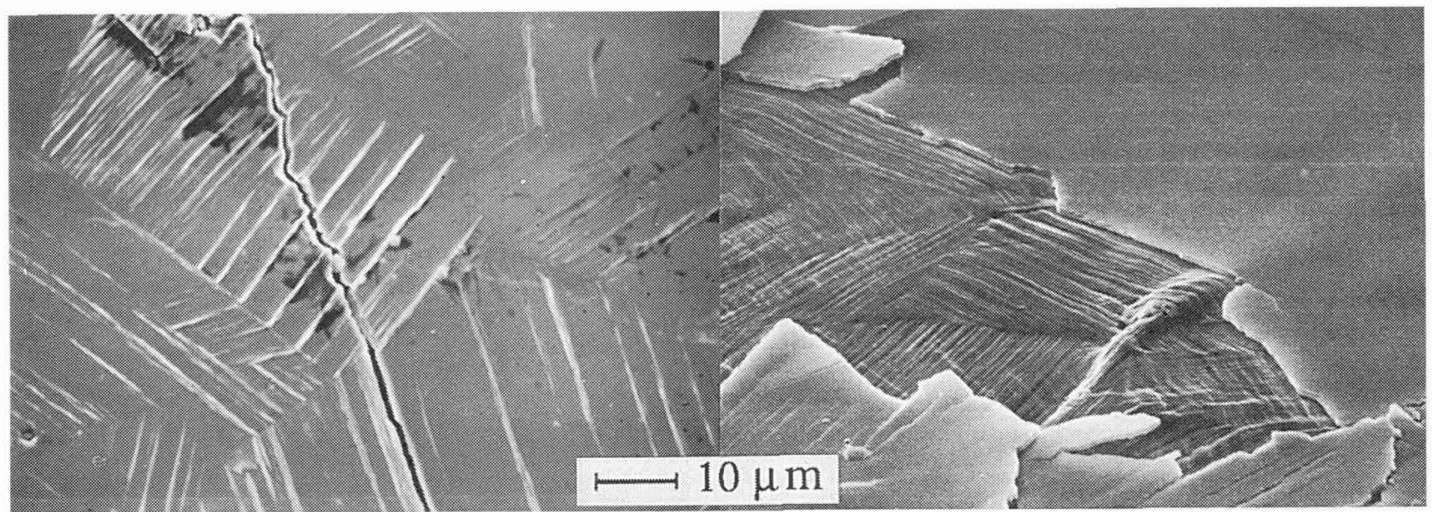

- a -

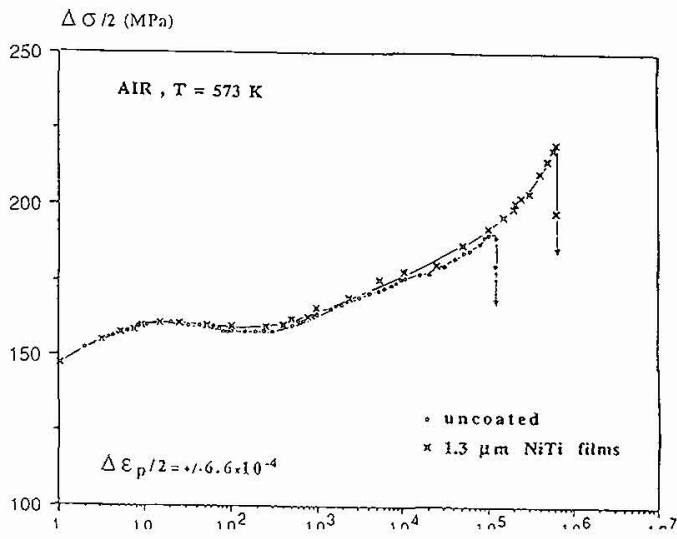

Fig. 4 - Typical aspect of the surface deformation at failure, $\Delta \varepsilon_{\mathrm{p}} / 2=6.6 \times 10^{-4}$

a) uncoated material, heteregeneous deformation.

b) $0.5 \mu \mathrm{m}$ - NiTi coated material homogeneous deformation.

Fig.5 - Cyclic behaviour of the untreated and NiTi 